\title{
ANALISIA PERSEDIAAN BAHAN BAKU CHIKI BALLS DENGAN METODE ECONOMIC ORDER QUANTITY (EOQ) PADA PT. INDOFOOD FRITOLAY MAKMUR
}

\author{
Edi Supriyadi $^{1)}$, Arif Sapriyadi' ${ }^{2}$ \\ Dosen Teknik Industri Universitas Pamulang \\ supriyadi.edi46@gmail.com \\ arifsapriyadi.94@gmail.com
}

\begin{abstract}
ABSTRAK
PT. Indofood Fritolay Makmur bergerak di Industri makanan ringan, dengan misi membuat produk berkualitas tinggi, inovatif, dan harga terjangkau sehingga menjadi pilihan pelanggan, serta memastikan ketersediaan produk untuk pelanggan domestik dan luar negeri. Dalam memenuhi permintaan kesediaan bahan baku dengan proses produksi haruslah seimbang dalam efisiensi penghematan biaya. Hal ini berakibat pada kelebihan persediaan bahan baku akibat kurang tepat dalam pengambilan keputusan persediaan. Hal ini di sebabkan oleh permintaan dari konsumen sehingga bahan baku pembelian berdasar pada konsumen saja.Terkadang perusahaan membeli persediaan bahan baku dalam jumlah yang relatif besar, sehingga menyebabkan pemborosan biaya penyimpanan bahan baku. Untuk itu penggunaan metode ABC (Activity Based Costing) dan Metode Economic Order Quantity (EOQ) dianggap cukup tepat dalam penanganan masalah persediaan. Rata-rata pembelian bahan baku Chiki Balls dengan metode Economical Order Quantity (EOQ) cukup efisien dalam pembelian bahan baku Chiki Balls dalam jumlah 32.317 Bacth dengan 28 kali pesan dalam satu tahun dengan menghabiskan biaya persediaan sebesar Rp. 3.696.433,--1tahun. Jika dibandingkan dengan kebijakan PT. Indofood Fritolay Makmur yang melakukan pembelian sebanyak 48 kali dalam setahun dengan jumlah 19.125 Batch menghabiskan biaya sebesar Rp.4.216.846,--/tahun. Maka dengan menghemat biaya persediaan sebesar Rp.520.413,--Itahun. Dengan metode Economical Order Quantity (EOQ), perusahaan harus menyediakan persediaan pengaman untuk memperlancar proses penjualan bahan baku Chiki Balls sebanyak 47.379 karton dan titik pemesanan kembali untuk mengantisipasi ketidak tersediaannya bahan baku pada supplier pada saat bahan baku Chiki Balls dalam jumlah 50.359 karton.
\end{abstract}

Kata kunci: $\quad$ Persediaan, Activity Based Costing (ABC),Eqonomic Order Quantity (EOQ).

\section{PENDAHULUAN}

PT. Indofood Fritolay Makmur merupakan perusahaan makanan ringan (Snack Food) perusahaan yang memproduksi makanan-makanan ringan bergerak dibidang retail penjualan chiki. PT. Indofood Fritolay Makmur didirikan 01 Februari 2002, dengan misi menyediakan produk yang berkualitas, inovatif, dan harga cukup terjangkau, dengan memastikan ketersediaan produk pelanggan domestik maupun luar negeri. Pemenuhan permintaan semakin meningkat perlunya ketersediaan bahan baku produksi. Hal ini mengakibatkan kelebihan persediaan bahan baku karena kurang tepat dalam pengambilan keputusan persediaan. Maka perlu adanya pengelolaan persedian bahan baku agar efisiensi pada persediaan bahan baku.
Metode ABC (Activity Based Costing) sangat tepat menangani masalah persediaan yang dihadapi oleh PT. Indofood Fritolay Makmur. Penentuan jumlah persediaan bahan baku yang maksimum.

\section{DASAR TEORI}

\section{A. Metode ABC (Activity Based Costing)}

Analisis ABC merupakan metode pembuatan grup atau penggolongan berdasarkan peringkat nilai dari nilai tertinggi hingga terendah dan dibagi.menjadi 3 kelompok besar yang disebut kelompok A, B dan C. Berikut penjelasan dari 3 kelompok tersebut:

1. Kelompok $\mathrm{A}$ adalah inventory dengan jumlah sekitar $2 \%$ dari item tapi 
mempunyai nilai investasi sekitar $8 \%$ dari total nilai inventory.

2. Kelompok B adalah inventory dengan jumlah sekitar $3 \%$ dari item tapi mempunyai nilai investasi sekitar $15 \%$ dari total nilai inventory.

3. Kelompok $\mathrm{C}$ adalah inventory dengan jumlah sekitar $5 \%$ dari item tapi mempunyai nilai investasi sekitar 5\% dari total nilai inventory (Suciati, 2 9).

Besarnya persentase adalah kisaran yang berbeda antara perusahaan satu dengan yang lainnya (Maimun, 2 8). Kelompok A adalah kelompok yang sangat kritis sehingga perlu pengontrolan secara ketat, dibandingkan kelompok B yang kurang kritis, sedangkan kelompok C mempunyai dampak yang kecil terhadap aktivitas gudang dan keuangan.

Maksud dari kelompok A adalah kelompok bahan baku yang bagus dan harus dikendalikan secara ketat. Sedang kelompok B laporan penjualan dan persediaannya dilaporkan secara rinci agar monitoring secara berkala pada setiap 1-3 bulan sekali dapat dilakukan. Pengendalian kelompok $\mathrm{C}$ lebih longgar tidak sesering kelompok $\mathrm{B}$ hanya dengan melakukan monitoring sekali-kali dan persediaan dapat dilakukan untuk 26 bulan. Prinsip ABC ini dapat diterapkan dalam pengelolaan pembelian, inventory, penjualan dan sebagainya.

\section{B. Metode Economic Order Quantity (EOQ)}

\section{Economic Order Quantity}

(EOQ)

adalah sebuah teknik kontrol persediaanyang meminimalkan biaya total dari pemesanan dan penyimpanan (Heizer dan Render, 2 8). Asumsi sebagai berikut:

1. Jumlah permintaan diketahui, konstan dan independen.

2. Waktu tunggu antara pemesanan dan penerimaan pesanan diketahui dan konstan.

3. Peneriman persediaan bersifat instan dan selesai seluruhnya.

4. Tidak tersedia diskon kuantitas.

5. Biaya variabel hanya untuk menyiapkan atau melakukan pemesanan (biaya penyetelan) dan biaya menyimpan persediaan dalam waktu tertentu (biaya penyimpanan atau membawa).

6. Kehabisan persediaan (kekurangan persediaan) dapat sepenuhnya dihindari jika pemesanan dilakukan pada waktu yang tepat.

Jika ukuran lot besar maka biaya pemesanan akan Turun dan biaya penyimpan naik. Sebaliknya, jika ukuran lot kecil maka biaya pemesanan akan naik dan biaya penyimpanan turun.

Untuk dapat menentukan jumlah pemesanan atau pembelian yang optimal pada setiap pemesanan diperlukan perhitungan kuantitas pembelian optimal yang ekonomis atau Economic Order Quantity (EOQ). Adapun langkah-langkahnya sebagai berikut:

$$
\mathrm{Q}=\frac{\sqrt{2 D S}}{H}
$$

Keterangan:

$$
\begin{array}{ll}
\text { EOQ } & =\text { Jumlah pembelian optimal yang } \\
& \text { ekonomis. } \\
\mathrm{Q} & =\text { Jumlah optimum unit per pesanan. } \\
\mathrm{D} & =\text { Jumlah permintaan/penggunaan } \\
& \text { suatu periode. } \\
\mathrm{S} & =\begin{array}{l}
\text { Biaya pemesanan untuk setiap } \\
\text { pesanan. }
\end{array} \\
\mathrm{H} & =\begin{array}{l}
\text { Biaya penyimpanan per unit per } \\
\text { tahun. }
\end{array}
\end{array}
$$

Frekuensi pembelian yang optimal (I) dapat diperoleh setelah nilai Q optimal diketahui. Rumusnya sebagai berikut:

$$
\mathrm{I}=\frac{D}{Q}
$$

Keterangan:

$\mathrm{F}=$ Frekuensi pembelian

$\mathrm{Q}$ = Jumlah barang pada setiap kali.pesan

$\mathrm{D}=$ Jumlah kebutuhan material dalam Satuan unit per tahun.

$\mathrm{S}$ = Biaya pemesanan untuk setiap kali pesan

$\mathrm{H}$ = Biaya penyimpanan per unit per tahun

\section{Safety Stock (SS)}

Persediaan pengaman adalah menetapkan penggunaan selama lead time yang kemudian ditambah dengan penggunaan selama periode tertentu sebagai safety stock dan persediaan tambahan. Menurut Assauri (2 4), jika safety stock dan standar lead time diketahui dan bersifat konstan persediaan ekstra yang 
disimpan sebagai jaminan atas fluktuasi permintaan. Maka rumus safety stock sebagai berikut:

$$
\mathrm{SD}=\frac{\sqrt{\sum(x-\bar{x})^{2}}}{n}
$$

Keterangan:

$S D=$ Standar Deviasi

$\mathrm{X}=$ Pemakaian Sesungguhnya

$\bar{X} \quad=$ Perkiraan Pemakaian

$\mathrm{N} \quad=$ Jumlah Data

Sedangkan rumus yang digunakan untuk menghitung persediaanpengaman sebagai berikut:

$Z \sigma \quad=S D \times Z$

$Z \sigma \quad=$ Persediaan Pengaman

$S D=$ Standar Deviasi

$Z \quad=$ Standar Deviasi diatas rata-rata

\section{Reorder Point (ROP)}

ROP atau titik pemesanan kembali adalah titik minimum atau batas dari jumlah persediaan bahan baku yang ada pada saat pemesanan harus kembali dan ditentukan dengan cermat. Perhitungan ROP atau titik pemesanan kembali menurut Heizer dan Render (2 1 ) sebagai berikut:

$$
\mathrm{ROP}=(\mathrm{LT} x \mathrm{~d})+\mathrm{SS}
$$

Keterangan:

$$
\begin{array}{ll}
\mathrm{ROP} & =\text { Reorder point } \\
\mathrm{d} & =\text { Permintaan harian } \\
\mathrm{LT} & =\text { Lead Time } \\
\mathrm{SS} & =\text { Safety stock }
\end{array}
$$

\section{E. Kerangka Fikir}

Kerangka fikir pada penelitian ini dapat dilihat pada Gambar 2.1. berikut:

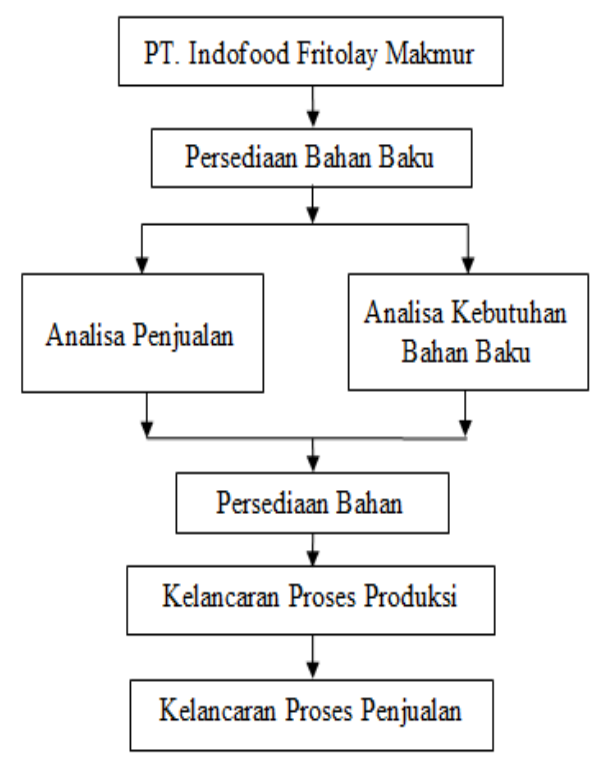

(Sumber: Hasil Pengolahan Data)

Gambar 2.1 Kerangka Fikir

\section{METODOLOGI PENELITIAN DAN TEKNIK PEGUKURAN}

\section{A. Lokasi dan Waktu Penelitian}

Agar penelitian ini dilakukan dengan fokus, maka ruang lingkup penelitian dibatasi sebagai berikut:

1. Lokasi

Penyusunan penelitian dilakukan di PT. Indofood Fritolay Makmur.

2. Waktu Penelitian

Penelitian dilakukan pada bulan Januari sampai bulan Juni 218.

3. Tempat Penelitian

Penelitian bertempat di PT. Indofood Fritolay Makmur, perusahaan yang memproduksi makanan ringan.

4. Objek Penelitian

Objek penelitian adalah analisa persediaan barang bahan baku makanan ringan (Chiki Snack) dengan menggunakan metode EOQ.

\section{B. Jenis Penelitian}

Dalam melakukan penelitian, metode yang digunakan adalah sebagai berikut:

1. Metode Analisis, yang terdiri dari:

a. Metode Deskriptif

Metode ini menggambarkan data masalah yang ada saat penelitian dilakukan (data aktual yang dianalisis untuk menguji hipotesis yang dilakukan) untuk melihat keadaan serta fakta-fakta yang ada diperusahaan. 
b. Metode Historis

Mengumpulkan data baik data perusahaan pada saat ini maupun data pada masa lalu untuk melihat perkembangan perusahaan.

2. Teknik Pengolahan Data

Teknik pengolahan ini menggunakan teknik pengolahan data kuantitatif yang merupakan pengolahan secara perhitungan dengan data berupa angka.

\section{Teknik Pengumpulan Data}

Dalam penelitian ini teknik yang dipakai untuk mengumpulkan data adalah:

1. Penelitian Kepustakaan (Library Research) Penulis mempelajari, meneliti dan menelaah berbagai sumber berupa buku-buku, jurnal penelitian terdahulu yang menujang dan berhubungan dengan redesain bangku ergonomis.

2. Penelitian Lapangan (Fied Research)

Penulis melakukan observasi terhadap permasalahan secara langsung ke objek penelitian dan melakukan pengukuran langsung di lapangan.

\section{Data dan Sumber Data}

Maksud dari data penelitian ini adalah data yang diperoleh penulis. Pada penelitian ini penulis menggunakan dua sumber data yaitu data primer dan data sekunder. Teknik pengumpulan data yang dilakukan terdiri atas:

1. Data Primer

Data primer diperoleh dari tempat penelitian dengan melakukan pengamatan dan wawancara dengan mengajukan pertanyaan kepada pimpinan dan karyawan yang berkaitan dengan objek penelitian dalam perusahaan terutama administrasi gudang Raw Material. Adapun cara-cara yang dilakukan dalam pengumpulan data primer ini sebagai berikut:

a. Observasi Lapangan

Teknik ini mengandalkan pengumpulan data dengan cara langsung turun ke objek penelitian dengan tujuan mendapatkan data aktual yang diperlukan.

b. Interview

Interview merupakan pengumpulan data wawancara langsung dengan narasumber yang berkaitan dengan kasus yang diteliti. c. Dokumentasi

Dokumentasi merupakan catatan atau arsip perusahaan yang menjadi data pendukung penelitian.

2. Data Sekunder

Data sekunder merupakan kumpulan data yang diperoleh dengan cara hasil studi kepustakaan. Adapun sumber data yang digunakan dalam penelitian ini diperoleh dari:

a. Studi Pustaka

Sumber data yang berasal dari buku-

buku refersnsi yang relevan dan

mendukung dengan objek penelitian.

b. Media Internet

Media internet merupakan sumber data

yang berasal dari berbagai media

internet baik berupa jurnal maupun

artikel yang mendukung penelitian.

\section{E. Flow Chart Penelitian}

Flow chart penelitian yang dilakukan di PT. Indofood Fritolay Makmur terdapat pada Gambar 3.1.

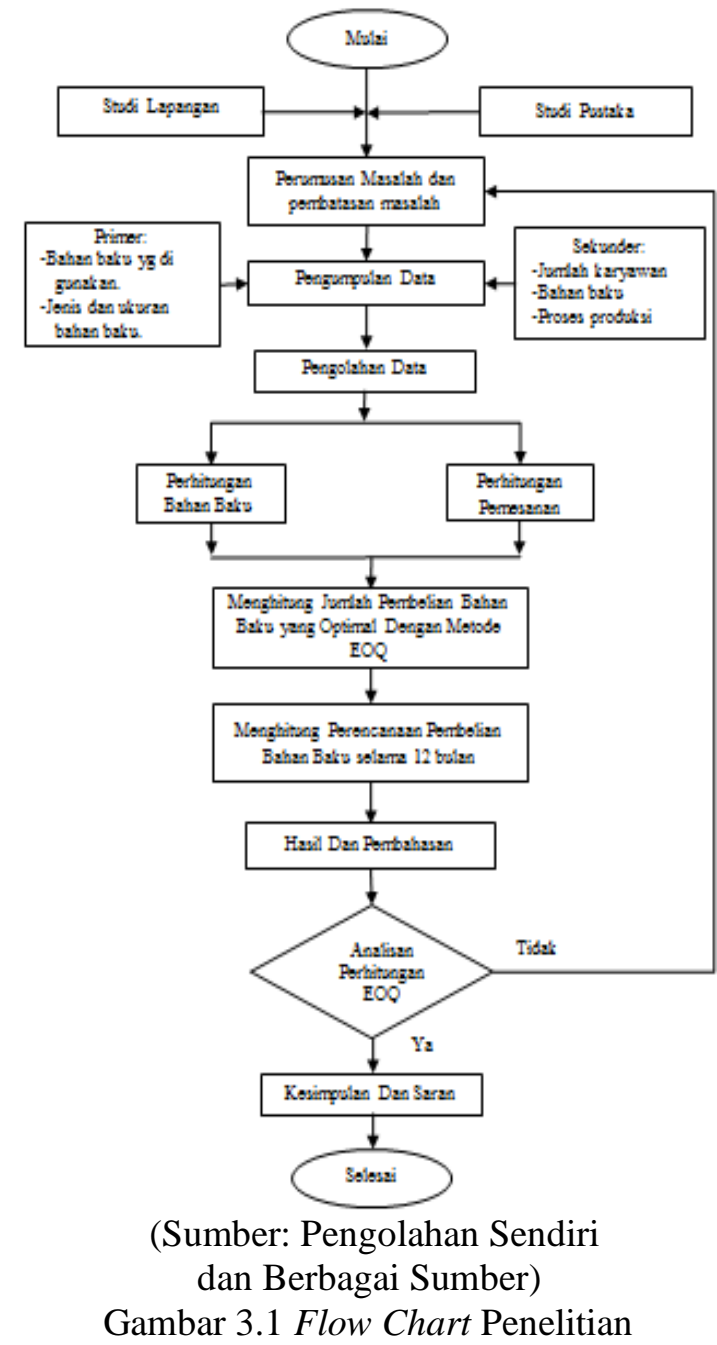

Gambar 3.1 Flow Chart Penelitian 


\section{PEMBAHASAN DAN HASIL}

\section{A. Data Permintaan Konsumen}

Kenaikan permintaan biasanya terjadi pada bulan Januari dan bulan Juli. Permintaan tersebut biasanya melebihi kapasitas produksi. Dan pada tengah permintaan akan menurun, maka akan mempengaruhi kebutuhan bahan baku setiap bulannya. Seperti pada perusahaan umum lainnya tidak menggunakan metode $E O Q$ untuk mengendalikan persediaan bahan baku Chiki Balls. Berikut ini adalah data aktual jumlah permintaan Chiki Balls tahun 218 pada PT. Indofood Fritolay Makmur, Seperti Tabel 4.1.

Tabel 4.1 Data Aktual permintaan bahan baku Chiki Balls tahun 218

\begin{tabular}{|r|l|c|}
\hline No & \multicolumn{1}{|c|}{ Bulan } & $\begin{array}{c}\text { Permintaan } \\
\text { (Batch)/kg }\end{array}$ \\
\hline 1 & Januari & 81.420 \\
2 & Febuari & 72.501 \\
3 & Maret & 76.106 \\
4 & April & 75.211 \\
5 & Mei & 77.283 \\
6 & Juni & 73.201 \\
7 & Juli & 80.117 \\
8 & Agustus & 75.103 \\
9 & September & 77.468 \\
10 & Oktober & 78.264 \\
11 & November & 75.183 \\
12 & Desember & 72.140 \\
\hline \multicolumn{2}{|l|}{ Total } & 913.997 \\
\hline
\end{tabular}

(Sumber: PT. Indofood Fritolay Makmur)

Untuk mengindentifikasi pola historis dari data aktual permintaan diatas, maka dibuat grafik dari data tersebut seperti ditunjukkan dalam Gambar 4.1 berikut:

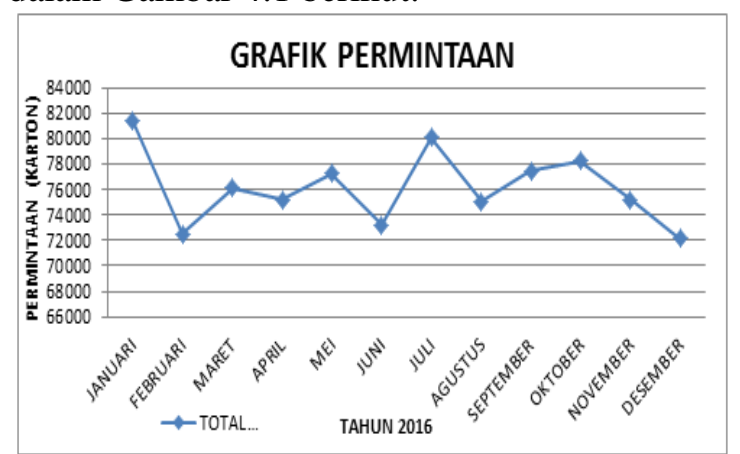

(Sumber: PT. Indofood Fritolay Makmur)

Gambar 4.1 Diagram Aktual Permintaan Bahan Baku ditahun 218

\section{B. Analisis ABC Bahan Baku Chiki Balls}

Berikut Tabel 4.2 yang menunjukkan analisis ABC bahan baku chiki balls.
Tabel 4.2 Analisis ABC Bahan Baku Chiki Balls

\begin{tabular}{|c|c|c|c|c|c|c|c|c|}
\hline$N_{0}$ & $\begin{array}{l}\text { Nama } \\
\text { Barang }\end{array}$ & $\begin{array}{c}\text { Pemaksian } \\
\text { Пahun }\end{array}$ & $\begin{array}{l}\text { Hargas } \\
\text { lunit }\end{array}$ & $\begin{array}{c}\text { Nilai } \\
\text { Pemaksian }\end{array}$ & $\begin{array}{c}\text { Nilai } \\
\text { Pemaksian } \\
\text { Yang Sadah } \\
\text { Dhurutkan }\end{array}$ & Nilai Komnlatif & $\begin{array}{c}\text { Nilai } \\
\text { Komnlat } \\
\text { if }(\%)\end{array}$ & $\begin{array}{l}\text { Kasyifika } \\
\text { si } \\
\text { Kategori }\end{array}$ \\
\hline 1 & $\begin{array}{l}\text { Tepunge } \\
\text { Jagung }\end{array}$ & 918.035 & 7.000 & 6.426 .245 .000 & 19.342.869.000 & 19.342 .869 .000 & $60 \%$ & A \\
\hline 2 & $\begin{array}{l}\text { Tepung } \\
\text { Beras }\end{array}$ & 921.089 & 21.000 & 19.342 .869 .000 & 6.426 .245 .000 & 25.769 .114 .000 & $80 \%$ & B \\
\hline 3 & Bumbu & 899.099 & 4.000 & 3.596 .396 .000 & 3.596 .396 .000 & 29.365 .510 .000 & $91 \%$ & \\
\hline 4 & Minyak & 927.323 & 3.000 & 2.781 .969 .000 & 2.781 .969 .000 & 32.147 .479 .000 & $98 \%$ & 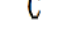 \\
\hline 5 & Air & 1.013 .723 & 50 & 50.686 .150 & 50.686 .150 & 32.198 .165 .150 & $100 \%$ & \\
\hline
\end{tabular}

(Sumber: PT. Indofood Fritolay Makmur)

Berdasarkan perhitungan diatas, dapat diketahui bahwa:

1. Klasifikasi kategori A yang sangat penting yaitu Tepung Jagung karena mempunyai persentase nilai komulatif sebesar $6 \%$,

2. Klasifikasi kategori B yang menengah yaitu Tepung Beras karena mempunyai nilai persentase komulatif sebesar $8 \%$.

3. Klasifikasi kategori $\mathrm{C}$ yaitu Bumbu, Minyak, dan Air tergolong dalam nilai persentase komulatif berturut-turut sebesar $91 \%, 98 \%$, dan $1 \%$.

Untuk mengetahui keandalan dari model peramalan yang dipilih, maka harus membuat peta kontrol Tracking Signaldan nilai-nilai Tracking Signal untuk model analisis garis kecendrungan ditunjukan dalam tabel 4.3 peta kontrol tracking signal dapat dilihat pada gambar dibawah ini.

Tabel 4.3 Peta Kontrol Tracking Signal model peramalan

\begin{tabular}{|c|c|c|c|c|c|c|c|c|c|c|}
\hline I & $\mathrm{F}$ & A & $\begin{array}{l}\text { ERROR } \\
(\mathrm{E}=\mathrm{A}-\mathrm{F})\end{array}$ & $(\mathrm{A}-\mathrm{F})^{2}$ & $\begin{array}{c}\mid(\mathrm{A}- \\
(\mathrm{F} / \mathrm{A})) \mid\end{array}$ & RSFE & |ERROR| & $\begin{array}{c}\text { KCMI } \\
\mid \text { ERROR| }\end{array}$ & IAD & IS \\
\hline 1 & 76166,4 & 81420 & 5253,38 & 27600137,84 & 81419,06 & 5253,58 & 5233,58 & 5253,58 & 5233,38 & 1 \\
\hline 2 & 81367,5 & 72501 & $.8866,46$ & 78614186,82 & 72499,88 & $.3612,88$ & 8866,46 & 14120,04 & 7060,02 & 0,51 \\
\hline 3 & 72589,7 & 76106 & 3516,33 & 12364614,35 & 76105,05 & $.96,54$ & 3516,33 & 17636,38 & 5878,79 & $-0,01$ \\
\hline 4 & 76070,8 & 75211 & $.859,83$ & 739319,05 & 75209,99 & $.956,38$ & 859,83 & 18496,22 & 4624,05 & $.0,20$ \\
\hline 5 & 75219,6 & 77283 & 2063,40 & 4257626,30 & 72282,03 & 1107,02 & 2063,40 & 20559,62 & 4111,92 & 0,26 \\
\hline 6 & 77262,4 & 73201 & $.4061,36$ & 16494693,65 & 73199,94 & $.2954,35$ & 4061,36 & 24620,98 & 4103,49 & $.0,72$ \\
\hline 7 & 73241,6 & 80117 & 6875,38 & 47270937,33 & 80116,09 & 3921,04 & 6877,38 & 31496,37 & 499,48 & 0,87 \\
\hline 8 & 80048,2 & 75103 & $-4945,24$ & 24455459,35 & 75101,93 & $.1024,21$ & 4945,24 & 36441,62 & 4555,20 & $.0,22$ \\
\hline 9 & 75152,5 & 77468 & 2315,54 & 5361760,40 & 77467,03 & 1291,34 & 2315,54 & 38757,16 & 4306,35 & 0,29 \\
\hline 10 & 7744,8 & 78264 & 819,15 & 671015,69 & 78263,01 & 2110,49 & 819,15 & 39576,32 & 3957,63 & 0,53 \\
\hline
\end{tabular}

(Sumber: PT. Indofood Fritolay Makmur) 


$$
\begin{aligned}
& \text { F1 } \\
& \begin{aligned}
8142+7251+7616+75211+77283+7321 \\
=\frac{8117+7513+77468+78264+75183+7214}{12} \\
=76166 \\
\text { MAD }=\Sigma\left|\frac{A t-F t}{n}\right|=\frac{45722,86}{12}=381,24 \\
\text { Tracking Signal }=\frac{R S F E}{M A D}=\frac{-436,4}{12} \\
=
\end{aligned}
\end{aligned}
$$

Berikut ini adalah grafik Tracking Signal untuk mengetahui batas control atas dan control bawah di PT. Indofood Fritolay Makmur periode Januari sampai dengan Desember 218 yang dapat dilihat pada Gambar 4.2.

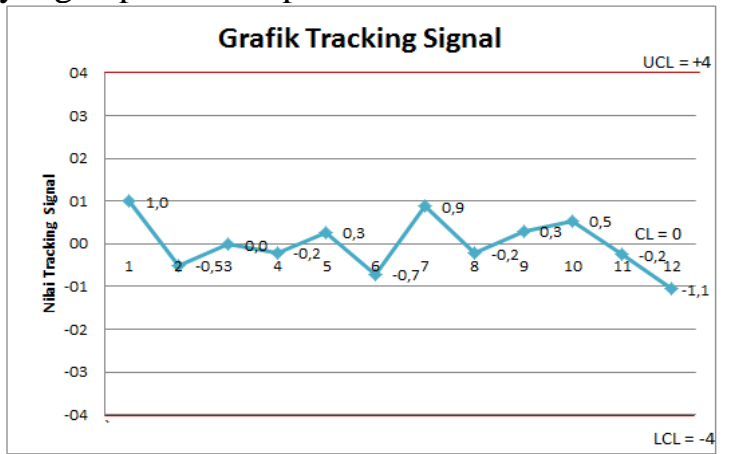

(Sumber: PT. Indofood Fritolay Makmur)

Gambar 4.6 Grafik Tracking Signal

Metode Economical Order Quantity (EOQ) ini akan dicoba diterapkan pada PT. Indofood Fritolay Makmur untuk mengendalikan persediaan bahan baku dan mengharapkan adanya hasil yang lebih efisien, baik untuk tingkat pembelian bahan baku, frekuensi pembelian, persediaan dan titik

\begin{tabular}{|c|c|c|c|c|}
\hline BULAN & $\begin{array}{l}\text { NDDEKS } \\
\text { WAKTU } \\
\text { (R) }\end{array}$ & $\begin{array}{c}\text { Permintaan } \\
\text { Actual } \\
\text { (A) }\end{array}$ & & $\begin{array}{c}\text { Ramalan } \\
\text { Berdasarkan } \\
\text { ES }(\mathrm{a}=0,99)\end{array}$ \\
\hline JANUARI & 1 & 81.420 & $\begin{array}{c}\text { Jumlah permintaan aktual : } 12 \\
\text { bulan }\end{array}$ & 76.166 \\
\hline FEBRUARI & 2 & 72.501 & $81.420-76.166 \times 0,99+76.166$ & 81.367 \\
\hline MARET & 3 & 76.106 & $72.501-81.367 \times \mathrm{b}, 99+81367$ & 72.590 \\
\hline APRIL & 4 & 75.211 & $76.106-72.590 \times 0,99+72.590$ & 76.071 \\
\hline MEI & 5 & 77.283 & $75.211-76.071 \times 0,99+76.071$ & 75.220 \\
\hline JUNI & 6 & 73.201 & $77.238-75.220 \times 0,99+75.220$ & 77.262 \\
\hline תII & 7 & 80.117 & $73.201-77.262 \times 0.99+77.262$ & 73.242 \\
\hline AGUSTUS & 8 & 75.103 & 80.117-73.242×0,99+ & 80.048 \\
\hline SEPTEMBER & 9 & 77.468 & $75.103-80.048 \times 0,99+80.048$ & 75.152 \\
\hline OKTOBER & 10 & 78.264 & $77.468-75.152 \times 0,99+75.152$ & 77.445 \\
\hline NOVEMBER & 11 & 75.183 & $78.264-77.445 \times 0,99+77.445$ & 78.256 \\
\hline \multirow[t]{2}{*}{ DESEMBER } & 12 & 72.140 & $75.183-78.256 \times 0,99+78.256$ & 75214 \\
\hline & TOTAL & & & 918033 \\
\hline
\end{tabular}
pemesanan kembali. Tabel 4.4 hasil peramalan bahan baku Chiki Balls untuk periode Januari sampai Desember 218 dapat dilihat dibawah ini.

Tabel 4.4 Peramalan permintaan bahan baku Chiki Balls tahun 218
(Sumber: PT. Indofood Fritolay Makmur)

\section{Pembelian Bahan Baku Chiki Balls}

PT. Indofood Fritolay Makmur melakukan pembelian bahan baku Chiki Balls rata-rata 4 kali dalam sebulan. Dengan frekuensi pemesanan tersebut, berarti pemesanan bahan baku chiki balls sebanyak 48 kali dalam setahun.

1. Jumlah pembelian bahan baku Chiki Balls:

$$
\begin{gathered}
Q \text { chiki balls }=\frac{\text { Total Kebutuhan }(D)}{\text { Frekuansi Pembelian }} \\
=\frac{91833}{48} \\
Q=19.125 \mathrm{batch} / \mathrm{bulan}
\end{gathered}
$$

2. Biaya Pembelian bahan baku Chiki Balls rata-rata ada pada tabel 4.5.

Tabel 4.5 Rincian Biaya Pembelian bahan baku Chiki Balls selama satu tahun

\begin{tabular}{|r|l|r|r|}
\hline No & Biaya & \multicolumn{1}{l|}{ Biaya Sekali Pesan } & \multicolumn{1}{l|}{ Harga } \\
\hline 1 & Biaya Telepon & Rp34.270 & Rp1.645.000 \\
\hline 2 & Biaya Adminitrasi & Rp30.791 & Rp1.478.000 \\
\hline \multicolumn{3}{|c|}{ Total Biaya } & Rp3.123.000 \\
\hline
\end{tabular}

(Sumber: PT. Indofood Fritolay Makmur)

Jadi biaya pembelian bahan baku Chiki Balls adalah:

$$
\begin{gathered}
S=\frac{\text { Total biaya pembelian chiki balls }}{\text { frekuensi pemesanan }} \\
S=\frac{3.123 .}{48} \\
S=R p .65 .62 \text { sekali pesan }
\end{gathered}
$$

3 Biaya Penyimpanan

Biaya penyimpanan adalah biaya yang dikeluarkan oleh perusahaan untuk melakukan penyimpanan bahan baku. Penyimpanan yang ditanggung PT. Indofood Fritolay Makmur antara lain: 
a. Biaya Listrik

Biaya listrik ini timbul karena penggunaan listrik selama bahan baku disimpan digudang untuk menunggu diproduksi. Perusahaan telah menetapkan biaya listrik $1 \%$ dari keseluruhan biaya listrik perusahaan. Jadi biaya listrik gudang adalah Rp. 68.25 . , - X $1 \%=$ Rp.6.825. , ,-/bulan. Rp. 6.825. ,-X $12=$ Rp. 81.9 . ,-/Tahun untuk bahan baku.

b. Biaya Air

Biaya air ini timbul karena air yang disimpan digudang air milik perusahaan lain,maka PT.Indofood Fritolay Makmur harus membayar sewa gudang baha

$\mathrm{n}$ baku air yang harus dibayar adalah $\mathrm{Rp}$. 63.888,88- X 3 hari = Rp. 1.916.666,66/bulan. Jadi Rp. 1.916.666,66- X 12 bulan = Rp. 23. .

Berikut ini adalah Tabel 4.6 rincian biaya penyimpanan bahan baku Chiki Balls di PT.Indofood Fritolay Makmur sebagai berikut.

Tabel 4.6 Rincian Biaya Penyimpanan bahan baku Chiki Balls

\begin{tabular}{|r|lr}
\hline \multicolumn{1}{|c|}{ No $_{0}$} & \multicolumn{1}{|c|}{ Biaya } & \multicolumn{2}{|c}{ Harga } \\
\hline 1 & Biaya Listrilk & Rp81.900.000 \\
\hline 2 & Biaya Air & Rp23.100.000 \\
\hline \multicolumn{2}{|c|}{ Jumlah Biaya } & Rp105.000.000 \\
\hline
\end{tabular}

(Sumber: PT. Indofood Fritolay Makmur)

Biaya Penyimpanan chiki balls adalah sebagai berikut:

$$
\begin{gathered}
\text { HChiki Balls }=\frac{\text { Total Biaya simpan }}{\text { Kebutuhan Chiki balls }} \\
=\frac{\mathrm{Rp} 15 . \cdot \operatorname{~}}{91833} \\
=\text { Rp. 114,38 per Batch }
\end{gathered}
$$

\section{Kebijakan Perusahaan dalam Pembelian}

PT. Indofood Fritolay Makmur melakukan pemesanan sebanyak 4 kali dalam sebulan hal ini menyebabkan kurang ekonomisnya biaya pemesanan. Hal tersebut dapat merugikan perusahaan karena harga pada waktu tertentu dapat mengalami kenaikan sehingga biaya pembelian yang meningkat yang dikeluarkan oleh PT. Indofood Fritolay Makmur. Untuk mengetahui total biaya persediaan berikut perincian biayanya:
1. Total Kebutuhan Chiki Balls (D) 918. 33 Batch

2. Total Pembelian bahan baku Chiki Balls rata - rata (Q)19.125 Batch

3. Biaya Tiap kali pesan bahan baku Chiki Balls (S)Rp. 65.62

4. Biaya Simpan bahan baku Chiki Balls (H)Rp. 114,38 per Batch

Maka perhitungan-perhitungan diatas total biaya persediaan adalah sebagai berikut:

TIC $=\frac{D}{Q} S+\frac{Q}{2} H$

TIC $=\frac{918.33}{19.125} 65.62+\frac{19.125}{2} 114.38$

$=$ Rp.3.123.88+Rp. 1.93 .758

$=\mathrm{Rp} .4 .216 .846$

Jadi, total biaya persediaan bahan baku Chiki Balls yang harus ditanggung perusahaan selama bulan Januari 217 sampai dengan Desember 217 adalah sebesar Rp. 4.216.846.

\section{E. Metode Economic Order Quantity (EOQ)}

Untuk menentukan jumlah persediaan bahan baku Chiki Balls yang paling ekonomis pada PT. Indofood Fritolay Makmur dapat menggunakan metode Economical Order Quantit (EOQ), metode ini dapat digunakan untuk menentukan jumlah pembelian persediaan yang meminimumkan biaya langsung. Penyiapan persediaan dan biaya pemesanan kembali. Langkah-langkah dalam metode EOQ sebagai berikut:

1. Analisa besarnya persediaan bahan baku

Chiki Balls adalah sebagai berikut:

a. Biaya simpan bahan baku Chiki Balls Per tahun $(H)$ RP. 114,38 per Batch

b. Biaya Tiap Kali Pesan bahan baku Chiki Balls (S) RP. 65.62

c. Total Kebutuhan bahan baku Chiki Balls (D) 918.33 Batch

Maka persediaan bahan baku Chiki Balls adalah sebagai berikut:

$$
\begin{gathered}
Q * \text { Chiki Balls }=\frac{\sqrt{2 D S}}{H} \\
=\sqrt{\frac{2 \times 918.33 \times 65.62}{114,38}} \\
=\sqrt{\frac{119.458 .126 .92}{114,38}} \\
=\sqrt{1.44 .396 .975} \\
=32.317 \text { Batch }
\end{gathered}
$$


2. Frekuesi pemesanan yang ekonomis untuk kebutuhan bahan baku Chiki Balls selama Januari 217 sampai dengan Desember 217 adalah sebagai berikut:

Frekuensi Chiki Balls = Jumlah Kebutuhan (D)

$=\frac{918.33}{32.317}$
$=28,4$ dibulatkan 28 kali pemesanan

3. Total Biaya Persediaan TIC (Total Inventory Cost)

Total biaya persediaan adalah jumlah persediaan yang meliputi biaya pembelian dan biaya penyimpanan barang. Langkah langkahnya adalah sebagai berikut:

a. Biaya simpan bahan baku Chiki Balls per tahun $(H)$ Rp.114,38 perBatch

b. Total kebutuhan bahan baku Chiki Balls (D) 918.33 Batch

c. Biaya tiap kali pesan bahan baku Chiki Balls (S) Rp.65.62

d. Persediaan bahan baku Chiki Balls yang optimal (Q) 32.317 Batch

Maka perhitungan Total Biaya Persediaan atau TIC (Total Inventory Cost) adalah sebagai berikut:

TIC Chiki Balls $=\frac{\mathrm{D}}{\mathrm{Q}^{*}} \mathrm{~S}+\frac{\mathrm{Q}^{*}}{2} \mathrm{H}$

$=\frac{918.33}{32.317} \times 65.62+\frac{32.317}{2} \times 114,38$

$=$ Rp. 1.848.224 +Rp.1.848.2 9

$=$ Rp.3.696.433.

4. Menentukan Persediaan Pengaman atau Safety Stock (SS)

Kebutuhan perusahaan akan adanya barang tidak akan sama setiap bulannya, selain itu bahan baku yang dipesan oleh PT. Indofood Fritolay Makmur belum tentu selalu dapat memenuhi kebutuhan. Hal ini perlu diantisipasi oleh manajemen perusahaan yaitu dengan menyediakan persediaan pengaman atau safety stock (SS), agar persediaan bahan baku tidak dalam keadaan kosong. Penentuan jumlah persediaan pengaman dilakukan dengan metode statistik yaitu dengan membandingkan pemkaian barang sesungguhnya dengan rata-rata penjualan Chiki Balls kemudian dicari berapa besarnya penyimpanan atau standar deviasi (SD). Standar deviasi dapat dihitung dengan rumus sebagai berikut:

Tabel 4.7 Perhitungan Standar Deviasi Pembelian bahan baku

\begin{tabular}{|c|c|c|c|c|c|}
\hline No & Bulan & $\mathbf{x}$ & $\overline{\mathrm{x}}$ & $x-\overline{\mathrm{x}}$ & $x-\overline{\mathrm{x}}^{2}$ \\
\hline 1 & Januari & 76166 & 19125 & 57041 & 3.253 .675 .681 \\
\hline 2 & Febuari & 81367 & 19125 & 62242 & 3.874 .066 .564 \\
\hline 3 & Maret & 72590 & 19125 & 53465 & 2.858 .506 .225 \\
\hline 4 & April & 76071 & 19125 & 56946 & 3.242 .846 .916 \\
\hline 5 & Mei & 75220 & 19125 & 56095 & 3.146 .649 .025 \\
\hline 6 & Juni & 77262 & 19125 & 58137 & 3.379 .910 .769 \\
\hline 7 & Juli & 73242 & 19125 & 54117 & 2.928 .649 .689 \\
\hline 8 & Agustus & 80048 & 19125 & 60923 & 3.711 .611 .929 \\
\hline 9 & September & 75152 & 19125 & 56027 & 3.139 .024 .729 \\
\hline 10 & Oktober & 77445 & 19125 & 58320 & 3.401 .222 .400 \\
\hline 11 & November & 78256 & 19125 & 59131 & 3.496 .475 .161 \\
\hline 12 & Desember & 75214 & 19125 & 56089 & 3.145 .975 .921 \\
\hline & Total & 918.033 & 229.500 & 688.533 & 39.578.615.009 \\
\hline
\end{tabular}

(Sumber: PT. Indofood Fritolay Makmur)

$$
\begin{aligned}
& \mathrm{SD}=\sqrt{\frac{\mathrm{X}-\bar{X}^{2}}{\mathrm{n}}} \\
& =\sqrt{\frac{39.578 .615 .9}{48}} \\
& =\sqrt{824.554 .479} \\
& =28.715,5=28.715 \text { (dibulatkan) }
\end{aligned}
$$

Dengan asumsi bahwa manajemen perusahaan menggunakan standar penyimpanan sebesar 5\% dengan standar deviasi sebesar 1,65. Maka:

$$
\begin{aligned}
\text { Safety Stock }(S S) & =\text { SD } \times \mathrm{Z} \\
& =28.715 \times 1,65 \\
& =47.379 \text { Batch }
\end{aligned}
$$

5. Analisa Titik Pemesanan Kembali atau $R e$ Order Point (ROP) Analisa titik pemesanan kembali atau Re Order Point (ROP) adalah saat pemesanan kembali yang tepat, ketika perusahaan sudah harus melakukan pemesanan kembali untuk helm yang terjual. Selama ini PT. Indofood Fritolay Makmur akan melakukan pemesanan bahan baku dalam waktu 7 hari sekali, dan lead time nya adalah 1 hari dari supplier sampai ke PT. Indofood Fritolay Makmur. Untuk menentukan Re Order Point (ROP) dapat dihitung dengan rumus berikut.

$$
\mathrm{ROP}=
$$

(Pemakaian Rata-Rata Perhari X Lead Time) + Safety Stock

a. Total kebutuhan bahan baku Chiki Balls (D):918. 33 batch

b. Total hari kerja selama setahun:3 8 hari Pemakaian bahan baku rata-rata perhari: $d=\frac{\mathrm{D}}{\text { Jumlah hari kerja selama } 1 \text { tahun }}$ $d=\frac{918.33}{38}$

$d=2.98$ karton per hari

Perhitungan titik pemesanan kembali atau Re Order Point (ROP) 
$\mathrm{U}$ : Pemakaian bahan baku Chiki Balls ratarata perhari: 2.98 Batch

L : Lead Time: 1 Hari

SS: Safety Stock (SS) bahan baku Chiki Balls:47.379 Batch

Re Order Point (ROP) Bahan baku Chiki Balls

$\mathrm{ROP}=(\mathrm{UxL})+\mathrm{SS}$

$=(2.98 \times 1)+47.379$

$=2.98+47.379$

$=5.359$ Batch

\section{F. Tabel Perbandingan Persediaan Bahan} Baku Chiki Balls

Perbandingan persediaan bahan baku Chiki Balls antara kebijakan perusahaan dengan metode Economica Order Quantity (EOQ). Dari hasil perhitungan yang telah dilakukan, maka dapat dilihat perbandingan persediaan bahan baku Chik Balls dan antara sebelum dengansesudah menggunakan metode Economical Orde Quantit (EOQ). Adapun perbandingan sebelum dan sesudah menggunakan metode Economical Order Quantity (EOQ) dapat dilihat pada Tabel 4.8.

Tabel 4.8 Hasil Penelitian Kebijakan Perusahaan dengan Metode EOQ

\begin{tabular}{|c|l|c|c|c|}
\hline No & \multicolumn{1}{|c|}{ Keterangan } & Kebijakan & EOQ & Selisih \\
\hline 1 & $\begin{array}{l}\text { Pembelian rata-rata bahan } \\
\text { baku Chiki Balls }\end{array}$ & 19.125 & 32.317 & -13.192 \\
\hline 2 & Frekuensi Pembelian & 48 & 28 & 23 \\
\hline 3 & Total Biaya Persediaan & 4.216 .846 & 3.696 .433 & 520.413 \\
\hline 4 & Safety Stock & - & 47.379 & - \\
\hline 5 & Re Order Point (ROP) & - & 50.359 & - \\
\hline
\end{tabular}

(Sumber: PT. Indofood Fritolay Makmur)

\section{KESIMPULAN DAN SARAN}

\section{A. Kesimpulan}

Berdasarkan hasil perhitungan Economical Order Quantity (EOQ) untuk bahan baku Chiki Balls jadi dapat dilihat dibawah ini:

1. Pembelian rata-rata bahan baku Chiki Balls dengan metode Economical Order Quantity (EOQ) lebih efisien untuk pembelian bahan baku Chiki Balls dalam jumlah 32.317 Bacth dengan 28 kali pesan dalam satu tahun dan hanya menghabiskan biaya persediaan sebesar Rp. 3.696.433,-/tahun. Jika dibandingkan dengan kebijakan PT. Indofood Fritolay Makmur yang melakukan pembelian sebanyak 48 kali dalam waktu 1 tahun dengan jumlah 19.125 Batch yang menghabiskan biaya sebesar Rp. 4.216.846,- /tahun. Maka dengan menghemat biaya persediaan sebesar Rp.52 .413,-/tahun.

2. Persediaan pengamanan atau Safety Stock (SS) dengan metode Economical Order Quantity (EOQ), perusahaan harus mengadakan persediaan pengaman untuk memeperlancara proses penjualan dimana untuk bahan baku Chiki Balls 47.379 Batch. Adanya titik pemesanan kembali dengan menggunakan metode Economical Order Quantity (EOQ) untuk mengantisipasi ketidaktersediaannyabahan baku pada supplier pada saat bahan Baku Chiki Balls dalam jumlah 5 .359 Batch.

\section{B. Saran}

Untuk pengembangan lebih lanjut pada penelitian ini ada beberapa hal yang dapat dilakukan diantaranya sebagai berikut:

1. Diharapkan pada penelitian ini dapat bermanfaat bagi perusahaan industri manufaktur. Karena manajemen persediaan sangatlah penting untuk menunjang kelancaran produksi dan distribusi agar menjadi lebih baik. Sebelum melakukan pengadaan bahan baku alangkah lebih baik menghitung persediaan optimum agar biaya persediaan tidak terlalu tinggi sehingga dapat menggunakan bahan baku secara optimum.

2. Untuk penelitian selanjutnya diharapkan untuk menambahkan metode penelitian, guna mendapatkan hasil penelitian yang lebih baik lagi dan lebih optimum.

\section{DAFTAR PUSTAKA}

Amithya Paramasatya (2 6). "Aplikasi Analisis Pareto Dalam Pengendalian Inventori Bahan Baku Pada Bisnis Restoran Dengan Metode ABC". Bandung: Universitas Katolik Parahyangan.

Andy Wijaya, Muhammad Arifin (2 4). "Sistem Informasi Perancangan Persediaan BarangPada PT. Panamas Dwitama Distrindo". Surabaya: Universitas Sekolah Tinggi Ilmu Komputer.

Candra, A. (2019). Pengendalian Persediaan Material Pada Produksi Hot Mix Dengan Pendekatan Metode Economic Order Quantity (Eoq). Jitmi (Jurnal Ilmiah Teknik Dan Manajemen Industri), 1(2), 145-153. 
Carien Valerie Sakkung (2 11). "Perbandingan Metode Economic Order Quantity (EOQ) Dan Just In Time (JIT) Terhadap Efisiensi Biaya Persediaan Dan Kinerja Non-Keuangan Pada PT. IndotoTirtaMulia”. Bandung: Universitas Kristen Maranatha.

Ikhsan Aditama, Wakhid Ahmad Jauhari (2 6). "Perencanaan Kebijakan Persediaan Bahan Kimia Menggunakan Metode Continuous Review dan ABC Pada Departemen Printing-Dyeing PT. Kusmahadi Santosa”. Surakarta: Universitas Sebelas Maret.

Oviliani Yenty Yuliana (2 ). "Rancang Sistem Informasi Persediaan Bahan Baku Dan Ramalan Kebutuhan Produk Terkomputerisasi PT. KPL Dengan Metode EOQ, MRP”. Surabaya: Universitas Kristen Petra.

Siska Tristanti Sutjiadi, BajuBawono. (2 14). "Pengendalian Persediaan Bahan Baku Roti Pada UD Minang Jaya".Yogyakarta: Universitas Atma Jaya.

TaufiqAji, Niezar Moch. (2 1 ). "Evannaza Klasifikasi ABC Dengan Pendekatan

\begin{tabular}{|c|c|}
\hline $\begin{array}{l}\text { Keputusan } \\
\text { Persediaan }\end{array}$ & Multikriteria \\
\hline & ".Yogyakarta: \\
\hline $\begin{array}{l}\text { Universitas } \\
\text { Kalijaga. }\end{array}$ & Islam Negeri \\
\hline
\end{tabular}

Utari, A. (2 14). "Pengendalian Persediaan Obat Paten dengan Metode Analisis ABC, Metode Economic Order Quantity (EOQ), Buffer Stock dan Reorder Point (ROP) di Unit Gudang Farmasi RS. Zahirah".Jakarta: Universitas Islam Negeri Syarif Hidayatullah.

Waridad Umais (2 15). “Analisis Pengendalian Persediaan Bahan Baku Beras Dengan Metode Economic Order Quantity (EOQ) Multi Produk Pada CV Djawa Dwipa Jember".Jember: Universitas Jember.

http://literaturbook.blogspot.co.id/2 14/12/pengertian-efektivitas-danlandasan.html?m=1

http://skripsi-manajemen.blogspot.co.id/2 11/ 2/pengertian-kinerja.html

http://ilmumanajemenindustri.com/pengertiansistem-bahan-baku-dan-caramembuatnya.htm 